\title{
CALS-Technology as a Basis of Creating Modules for Assessment of Construction Products Quality, Regulation of Organizational, Technological and Business Processes of Stakeholders of Construction Industry Under the Conditions of Cyclical and Seasonal Variations
}

\author{
Viktoriya Tytok $^{1}$, Nadiia Bolila ${ }^{2}$, Dmytro Ryzhakov ${ }^{3}$, Vadym Pokolenko ${ }^{4}$, Igor Fedun ${ }^{5}$ \\ ${ }^{1}$ Department of Construction Economics, Kyiv National University of Construction and Architecture, Kyiv, \\ Ukraine, victoriatytok@gmail.com \\ ${ }^{2}$ Department of Construction Economics, Kyiv National University of Construction and Architecture, Kyiv, \\ Ukraine, nadezda.bolila@gmail.com \\ ${ }^{3}$ Department of Strategic Planning and Construction Development LLC "Ukrainian Investment and Engineering \\ Company", Kyiv, Ukraine \\ ${ }^{4}$ Department of Management in Construction, Kyiv National University of Construction and Architecture, Kyiv, \\ Ukraine, Galyna_Ryzhakova@ukr.net \\ ${ }^{5}$ Department of World Economy, Kyiv National University of Trade and Economics, Kyiv, Ukraine, \\ fil_2604@ukr.net
}

\begin{abstract}
This article is dedicated to the problem of the presentation and assessment business processes ability of complex project and production management systems, construction products quality assessment, organizational and technological process regulation in cyclical and seasonal variations. For solving this problem is proposed the multidimensional modeling which is based on CALS technology. The model contains the information base which is presented in a database that accumulates the information during the whole construction site life cycle and construction stakeholders (suppliers, construction companies, contractors, development companies and others). It is presented the approximate modular blocks «Seasonality definition», «Cyclicality», «Quality Assessment» as the components of CALS environment which involves also multidimensional database which is considered as the archive of construction sites, business processes, data about quality, cost, labor intensity and construction time divergences. This archive is designated for storage of the passive and active construction sites attributes. It is illustrated the application of CALS concept by the case of construction companies.
\end{abstract}

Key words : CALS, cyclicality, production and project management systems, seasonal variations, software module, quality.

\section{INTRODUCTION}

The current stage of construction projects organization and management within the framework of main construction stakeholders' collaboration is marked by transition to paperless technologies which ensure fast and unmistakable document processing of various types. One of such technologies is the CALS concept.

CALS (Continuous Acquisition and Life cycle Support) symbolizes two main ideas which fulfil CALS tasks. The first part of the term «CALS» (Continuous Acquisition) means constant efficiency (development) increase of either the product or the processes of interaction between the products supplier and the consumer during their whole life cycle. The second part of the term «CALS» (Life cycle Support) contributes the way of such development: implementation of new organizational methods of the information system designing, for example, distributed engineering or virtual working groups. This will lead to investment increase at the stage of the product creation and modernization but will allow to take into account the owner needs and operating conditions that, in turn, lead to the costs decrease at the stage of the product operation and maintenance and ultimately to the costs decrease during the whole product life cycle [1]. 
The main aim of CALS concept is the efficiency improvement of information system life cycle processes at the expense of the object's information management. The major destination of CALS idea realization is the transformation of information system life cycle through restructuring of the phases and procedures which are composed it [2]. There are such instruments for the implementation:

- computerization, which allows to increase the productivity of the converting information basis processes and operations;

- processes information integration, which provides common utilization of data;

- application of new models of the design processes organization.

The utilization of CALS concept by carrying out of construction objects of the industrial and civil destination is researched in papers [3-9]. Digitalization and digital transformation influence of construction processes on the development of the construction companies and other construction stakeholders is detected in papers [10-15]. The interaction of construction participants and the influence of organizational and technological factors on construction parameters are detailed in papers [16-18].

The analysis of the sources allows to determine that the application of the CALS-technologies in the construction allows considerably to reduce project scope because the description of many component parts of the equipment, machines and systems, which were designed earlier, are stored in the unified formats of the network server data which are available to each CALS-technology user. In this case is considerably facilitated problems solving:

- repairability;

- products integration into different functional system;

- adjustment to the evolving operating condition;

- integration of the highly specialized design organizations and so on [10].

However, CALS-technologies can be useful not only for the accumulation and transmission of the data about the construction objects and business processes, but also, they can be used for the evaluation of the compatibility with quality standards of construction products, internal and external business processes of the construction stakeholders. The interest is the data accumulation about the construction processes and respecting influence of such typical effects in the construction processes as cyclicality and seasonality that is the promising subfield of research.

\section{THE MAIN RESEARCH}

In the literature the term CALS is deciphered as "Continuous Acquisition and Life cycle Support" - constant information support of the supplies and life cycle or Ukrainian analog ISP (in Ukrainian language «IПВ») - informational support id the processes life cycle of the products. In paper [11] CALS is considered as the concept and the ideology of the informational support of the process life cycle of the products at all stages, which is based on the application of the common information space (integrated information environment) that is provided interaction common methods of all participants of this cycle - owners and suppliers (manufacturers) of the products, operational and repair staff which is fulfilled in the shape of the international standards that regulate rules of the mentioned interaction mainly through electronic data interchange.

In this research it is proposed to use this concept as the basis for the system development of the constant informational support of the life cycle at the level:

1) Organizational and technological processes.

2) Selected investment-construction projects.

3) Construction products.

4) Construction companies-stakeholders at each stage of their development.

In contrast to the application of the CALS technologies, standards and program-technical tools by the products designing where it is foreseen the possibility of the difficult projects shadowing by several working groups (parallel engineering) at the stage of design and production that reduces markedly time and costs for the creation, by the application CALS technologies for the formation of the evaluation system of the construction products quality, for the regulation of the organizational, technological and business processes of the construction stakeholders, it should be given the opportunity of parallel work for selected departments and specialists with informational parallel whereas it is appointed one decision-making center. Thus, the results of each separated group should be accumulated in the center. Based on the accumulated information it is made the decision regarding risk management by selected group or about the necessity to connect others participants to troubleshooting of the enterprise`s activities.

It is highlighted the following automation systems for incoming information processing in CALS [8]:

1. Automated calculations and analysis (CAE);

2. Computer-Aided Design (CAD);

3. Enterprise resource planning (ERP);

4. Manufacturing resource planning (MRP);

5. Supply chain management (SCM);

6. Owner relationship management (CRM) and so on.

This list is not limited to the called groups, it is much wider and is formed for each enterprise individually.

We propose to complete the subsystems «Enterprise resource planning» and «Manufacturing resource planning» with module «Quality control» (the information accumulation about sub-standard workmanship at the level of the separated organizational and technological processes, works, materials, products and components of the finished construction product and at the level of enterprise's quality evaluation of the business processes and so on) and to complete the subsystem 
«Automated calculation and analysis (CAE)» with module «Definition of cyclical and seasonal variations».

Processes diversity by operating, financial and investment enterprise`s activities and the necessity of the risk prevention require active informational interaction of all enterprise's departments and also key stakeholders, which have the greatest impact for construction processes with the purpose of the accumulation of the actual information.

For example, Figure 1 show the module «Seasonality definition» can include such components: source data about construction parameters (labor intensity, cost, duration) during the year, models of the seasonality definition, results conclusions about existence of seasonal variations or about the lack of them.

\section{Source data}

Seasonality indexes are calculated by the formula:

$\mathrm{I}_{\text {сез }}=\frac{\overline{\mathrm{y}}_{\mathrm{i}}}{\overline{\mathrm{y}}_{3}} \times 100$

where $\overline{y_{i}}-$ is the average value of the indicator for the i-th period;

$\overline{y_{3}}$ - the general average value for all years.

Seasonality range: $R_{\text {сез }}=I_{\text {сез } \max }-I_{\text {сез } \min }$

Linear seasonality index: $k_{\text {сез }}=\frac{\sum\left|I_{\mathrm{ces}}-100\right|}{4}$

Quadratic seasonality index: $k_{\text {сез кв }}=\sqrt[4]{\frac{\left(\sum\left|I_{\text {сез }}-100\right|\right)^{2}}{4}}$.

Holt Winters model

$\hat{r}_{n+1}=\left(u_{n}+t_{n}\right) \cdot y_{n-\lambda+1}$,

$u_{n}=\alpha \frac{r_{n}}{y_{n-\lambda}}+(1-\alpha)\left(u_{n-1}+t_{n-1}\right)$

$t_{n}=\beta\left(u_{n}-u_{n-1}\right)+(1-\beta) t_{n-1}$,

$y_{n}=\gamma \frac{r_{n}}{u_{n}}+(1-\gamma) y_{n-\lambda}$.

$y_{n}$ - smoothing seasonality;

$\gamma$-smoothing parameter, $\gamma \in[0,1]$;

$\lambda$ - seasonality period.

Result ए

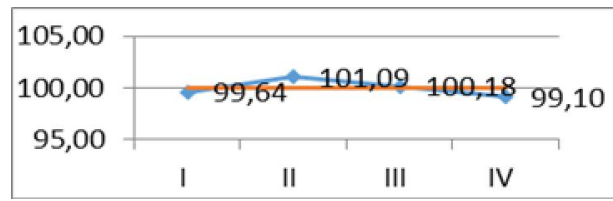

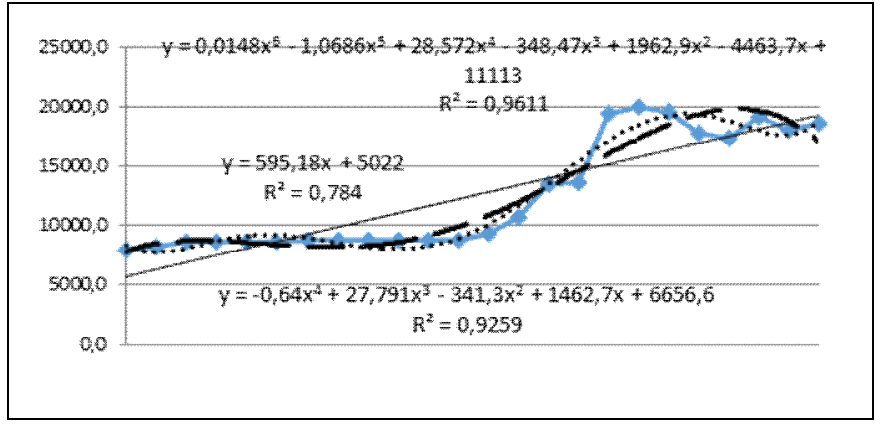

Figure 1: Module structure «Seasonality definition»

Figure 2 show module «Cyclicality definition» can include such components: source data about construction parameters (construction materials prices, business activities and so on) during 1-10 years, tools, which are intended for cyclicality definition, results - conclusions about the existence of cyclical variations or about the lack of them similar to previous module.

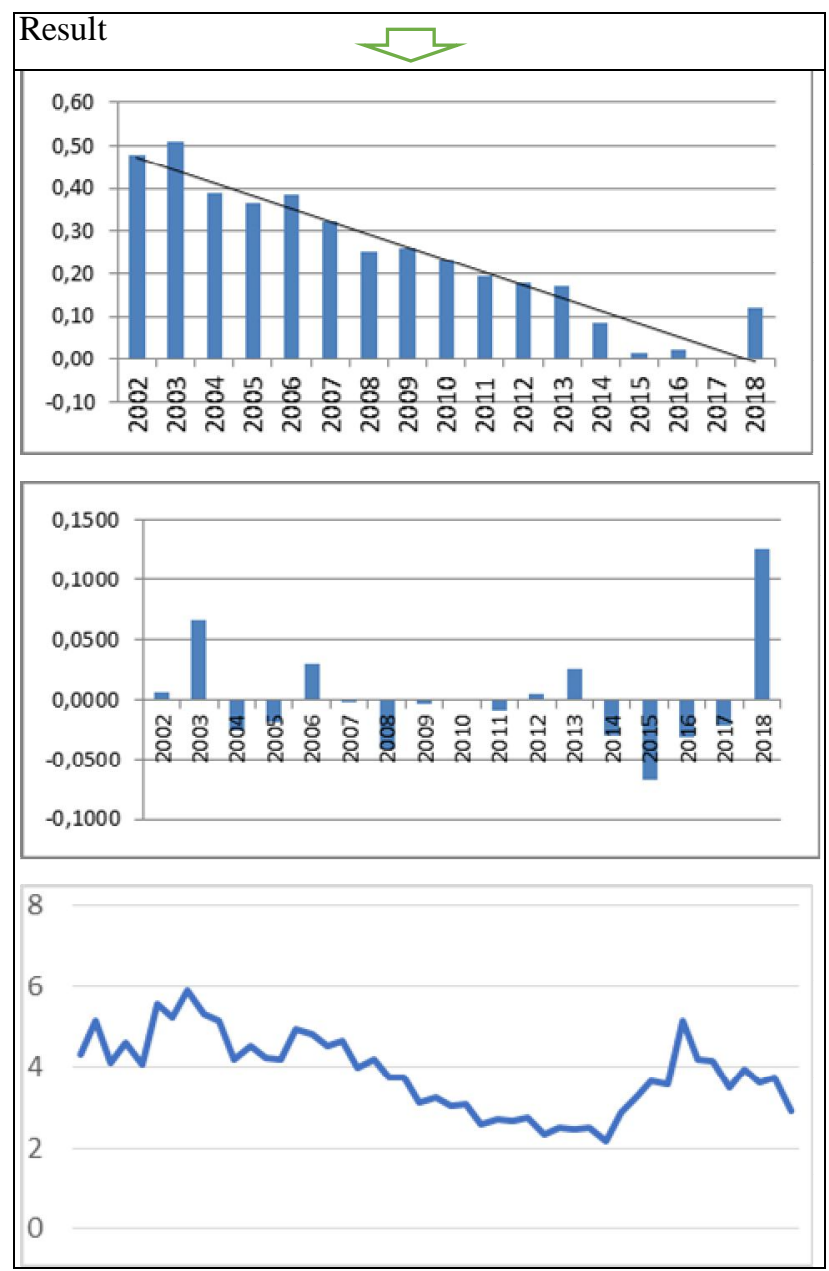

Figure 2: Module structure «Cyclicality definition» for aerated brick production enterprise

Module «Construction quality evaluation» can include the following components: source data about construction 
parameters (planed and actual parameters of the business processes, construction materials, products and components, building machines and machinery, labor force and so on), data about the deviations of business processes, organizational and technological processes of the construction stakeholders and consist of such measures:

- the contract examination;

- the construction site quality control program;

- the project quality control;

- the ensuring the quality of the raw products and materials;

- the ensuring the quality of the works;

- the ensuring the quality of the subcontracted works;

- the examination and control of the deviations;

- documentation on the quality and the completion of the construction works.

In view of the fact that every year are increasing the used and transferred information volume, the necessity of the creation of the integrated system support of the enterprise`s economic immunity at the different stages of the life cycle, of the systematization of the informational interaction of the components of the economic immunity system lead to the necessity of the creation of the integrated informational system (IIS). Such system should provide an opportunity to interact the different enterprise`s subsystems and to analyze threads from the interaction with different construction stakeholders (suppliers, owners, competitors, state and local authorities, financial lending organizations and o on) on the subject of the crisis prevention. All data in IIS is stored in the digital format. All processes of the information exchange through IIS have their final goal the greatest possible exclusion from the business practices the paper documents and the transition to direct paperless data exchange (as the example in the construction practice is the creation of the BIM-models of the objects [10]). The integrated informational system that is the basis for the system development of the support and evaluation of the construction products quality, of the regulation of the organizational, technical and business processes of the construction stakeholders can be considered as the package of the separated databases which has information about economic, financial, production environments, enterprise`s resources and processes, its state changes at any particular time that ensure correctness, relevance, conservation and accessibility of the data to those entities who are needed and allowed it. All data in IIS should be stored in the form of the informational objects but it should be ensured the possibility, if necessary, to output the data from each block on the screen or on the paper information medium.

The basis foundation for the introduction of the CALS-technologies is the functional and structural analysis of the processes control of the life cycle (LC) of the construction enterprise-stakeholders (on the example of construction company). On the bases of the analysis and classification of the life cycle management function is proposed the concept model of the CALS-technologies introduction as a basis for the development of the quality products evaluation system, of the regulation of the enterprise`s organizational, technological and business processes. The basis for the creation of the informational and digital models are formed with:

1) CALS basis principles (constant informational support of the enterprise's operation on the basis of the using integrated informational environment that ensures the cost reduction on the information collection and processing, the standardization of the informational description of the management objects; the focus on the existed programmable and technological solutions, for example, the interaction with suppliers and owners and so on) the paperless information demonstration, constant business processes reengineering in order to ensure the economic immunity;

2) basic management technologies (existed management technologies of the projects, resources, costs, logistical means for resources management and so on);

3) basic data management technologies (the formation and the support of the databases, the choice from the data sets of the indicators that indicate the enterprise`s risks, constant improvement of the selection algorithm).

As far as the system formation of the products quality evaluation, of the regulation of the organizational, technological and business processes during the whole enterpriser`s life cycle and this is enough long period of time, then appears the necessity to integrate the information flows and databases of all enterprise's departments in the single information space (accounting information system, dates about the movements of the logistical and labor resources, financial flows, engineering and technological documentations and other systems of the enterprise's management). To solve this task, it is necessary to introduce within the whole enterprise the single classification system of the operations, resources, financial and economic indicators, financial situation indicator, the single classification system of the risks and the quality evaluation. Also, it should be ensured the possibility to monitor the deviations from the plan at the level of the separated event or operation (for example, the monitoring of the period and the sum of the accounts receivable to the separated contract/supplementary agreement or the monitoring of the period of the materials supply on the site and so on). Thus, the basis should be a principle - the information about risks which appears at the any stage of operational, investment and financial enterprise`s activities is stored and should be available for all related contractors in accordance with their access rights.

The system implementation within enterprise requires the access providing of the different levels for the different groups of the workers. The integration within the single system of the financial, economic, accounting, legal, design, technological and management data leads to inevitably the necessity to 
protect the data confidentiality on the one hand and in the other hand to ensure the transparency which is needed for the formation of the effective prevention protection system. In addition, by the system implementation of the enterprise`s economic immunity information management it is necessary to implement own standards, methods and instructions for work with data because the copy the experience of the other companies for a number of reasons is almost impossible due to the differences in the organizational structure, operational activities specifics, accounting system, business process formation.

Today the main presentation form of the intellectual activities is the paper document which is prepared, controlled, agreed and approved in this form. Very often even by using computer systems the final result of the intellectual activities is formed in paper form at the following phases is changed again in electronic form. The amount of the transformation cycles and the labor intensity are very high. Then the transition from the paper document circulation to the electronic allows to speed up repeatedly the documents delivery to the right people, to ensure the parallelity of the discussion, control and the approval of the works results and to reduce considerably the processes length.

\section{RESULTS AND DISCUSSION}

As the formation basis of the informational and digital evaluation model of the construction products quality, of the regulation of the organizational, technological and business processes of the construction enterprises-stakeholders should be taken: basic principles of the CALS, basic management technologies, basic data management technologies, science-based management models and algorithms. It is proposed the concept basis of the informational model of the construction enterprise which is based on the CALS-ideology. It is offered to consider the integrated information system which is a basis for the formation the evaluation system of the construction products quality, of the regulation of the organizational, technological and business processes of the enterprises, as the separated database sets that include the information about financial and economic state, about production, investment, financial activities, resources and processes of the enterprise and its state changes at any particular time. The requirements for the informational model include correctness, relevance, conservation and accessibility of the data to those entities who are needed and allowed it.

\section{CONCLUSION}

The problem of the ability to demonstrate and to evaluate the business processes, management system of the projects and production, to evaluate the construction products quality, to regulate the organizational, technological processes in conditions of the cyclical and seasonal variations needs to be solves. For solving this problem, it is proposed the multidimensional modelling based on CALS technologies. The model which includes the informational system, is presented in the form of the database, which accumulates information during the whole construction object life cycle and construction enterprises-stakeholders (suppliers, construction companies, contractor and development organizations and so on). It is presented the approximate module components «Seasonality definition», «Cyclicality definition», «Quality evaluation», as the parts of the CALS environment that includes also the multidimensional database, which is viewed as the archive of the objects, business processes, data about the deviations of the quality, costs, labor intensity and construction period, and which is intended for attributes storage of the passive and active objects. It is highlighted the CALS concept application using the construction enterprises as an example.

\section{REFERENCES}

1. S. P. Stetsenko, V. V. Tytok, O. M. Emelianova, O. Yu. Bielienkova and T. Yu. Tsyfra. Management of Adaptation of Organizational and Economic Mechanisms of Construction to Increasing Impact of Digital Technologies on the National Economy, Journal of Reviews on Global Economic, № 9, 2020, pp. 149-164.

https://doi.org/10.6000/1929-7092.2020.09.15.

2. O. Yu. Belenkova. Theoretical approaches to ensuring the strategic competitiveness of enterprises on the basis of sustainable development, Management of complex systems development, 2020, Vol. 42, pp. 153-158.

3. R. Ya. Zeltser, O. Yu. Bielienkova, Ye. Novak and D. V. Dubinin. Digital Transformation of Resource Logistics and Organizational and Structural Support of Construction, Nauka i innovatsii, 2019, Vol. 15(5), pp. 38-51.

4. O. A. Tugai, P. Ye. Hryhorovskyi, V. O. Khyzhniak, S. P. Stetsenko, O. Yu. Bielienkova, O. S. Molodid and D. O. Chernyshev. Organizational and technological, economic quality control aspects in the construction industry, Lviv-Toruń: Liha-Pres, 2019, pp. 99-115.

5. O. Yu. Belenkova. Influence of seasonal fluctuations on current assets of a construction company, Investments: practice and experience, 2015, № 19 (May), pp. 48 - 53.

6. O. Bielienkova, S. Stetsenko, L. Sorokina, O. Molodid and N. Bolila. System of preventive action of construction enterprises on the basis of identification of anticrisis potential, Scientific Journal of Astana IT University, № 3, 2020, pp. 15-27. DOI: 10.37943/AITU.2020.53.13.002.

7. T. Honcharenko, Y. Chupryna, I. Ivakhnenko, $M$. Zinchenco and T. Tsyfra. Reengineering of the Construction Companies Based on BIM-technology, 
International Journal of Emerging Trends in Engineering Research, 8(8), August 2020, pp. 4166-4172.

https://doi.org/10.30534/ijeter/2020/22882020.

8. N. Shramko and M. Pichugina. Business, innovation, management: problems and prospects, in Coll. thesis add. International Science.-Practice. conf., Kyiv: KPI them. Igor Sikorsky, Polytechnic Publishing House, 2020, pp. 226-227.

9. S. Stetsenko, N. Bolila, L. Sorokina, T. Tsyfra and O. Molodid. Monitoring mechanism of resilience of the anti-crisis potential system of the construction enterprise in the long-term period, Economics, finance and management review, 2020, № 3, pp. 31-42.

10. N. V. Bolila. Functional-operational transformation of construction enterprise management systems based on CALS-technologies, Management of complex systems development, Vol. 40, 2019, pp. 156 -159.

11. N. O. Chorna. Estimation of possibility of application of CALS-technologies to the decision of problems of distributed management. Management of complex systems development, Vol. 8, 2011, pp. 97-100. URL: http://nbuv.gov.ua/UJRN/Urss_2011_8_21.

12. I. L. Fedun, Y. I. Holovnia, O. V. Diachenko, M. G. Slokva and N. P. Reznik. Development of public-private partnerships in the agrarian sector of Ukraine: institutional aspect. International Journal of Advanced Science and Technology, Vol. 29, No. 6s, 2020, pp. 1116-1125.

http://sersc.org/journals/index.php/IJAST/article/view/9 201

13. D. Chernyshev, D. Ryzhakov, O. Dikiy, O. Khomenko and S. Petrukha. Innovative Technology for Management Tools of Commercial Real Estate in Construction, International Journal on Emerging Trends in Engineering Research, 8(9), September 2020, pp. 4967-4973.

https://doi.org/10.30534/ijeter/2020/13892020.

14. J. Marchuk, D Ryzhakov, G. Ryzhakova and S. Stetsenko. Identification of the basic elements of the innovation-analytical platform for energy efficiency in project financing, Investment Management and Financial Innovations, Vol. 14, Issue 4, 2017, pp. 12-20. http://dx.doi.org/10.21511/imfi.14(4).2017.02.

15. D. Ryzhakov, O. Dikiy, M. Druzhynin, H. Petrenko and $\mathrm{T}$. Savchuk. Innovative tools for management the lifecycle of strategic objectives of the enterprise-stakeholder in construction, International Journal on Emerging Trends in Engineering Research, 8(8), 2020, pp. 4526-4532. https://doi.org/10.30534/ijeter/2020/78882020.

16. I. V. Novikova, O. M. Pietukhova, M. V. Apostol, I. L. Fedun and A. V. Cherkasov. Methodical bases of Formation of Tasks and Development of Risk-oriented Strategy of Development of the Enterprises in the Conditions of Internationalization and Economic Globalization, Journal of Advanced
Research in Dynamical and Control Systems, Vol. 12-7-Special Issue, 2020, pp. 405-411, https://www.ijeat.org/wp-content/uploads/papers/v8i6/F 9057088619.pdf.

17. O. Terentyev, S. Tsiutsiura, T. Honcharenko and T. Lyashchenko. Multidimensional Space Structure for Adaptable Data Model, International Journal of Recent Technology and Engineering (IJRTE), Vol. 8 Issue 3, pp. 7753-7758, September 2019. https://www.ijrte.org/wp-content/uploads/papers/v8i3/C 6318098319.pdf.

18. G. Ryzhakova, V. Pokolenko, O. Malykhina, K. Predun and N. Petrukha. Structural Regulation of Methodological Management Approaches and Applied Reengineering Tools for Enterprises-Developers in Construction, International Journal of Emerging Trends in Engineering Research, Vol. 8. No. 10, pp. 7560-7567, October 2020. https://doi.org/10.30534/ijeter/2020/1428102020. 